\title{
Bacteriophages, phage endolysins and antimicrobial peptides - the possibilities for their common use to combat infections and in the design of new drugs
}

\author{
Tomasz Mirski ${ }^{1, A-D \oplus}$, Lidia Mizak ${ }^{1, A, D-F} \oplus$, Aleksandra Nakonieczna ${ }^{1, E \oplus}$, Romuald Gryko ${ }^{1, E \oplus ~}$ \\ 1 Biological Threat Identification and Countermeasure Centre of the Military Institute of Hygiene and Epidemiology, \\ Puławy, Poland \\ A - Research concept and design, B - Collection and/or assembly of data, C - Data analysis and interpretation, \\ $D$ - Writing the article, E - Critical revision of the article, F - Final approval of article
}

Mirski T, Mizak L, Nakonieczna A, Gryko R. Bacteriophages, phage endolysins and antimicrobial peptides - the possibilities for their common use to combat infections and in the design of new drugs. Ann Agric Environ Med. 2019; 26(2): 203-209. doi: 10.26444/aaem/105390

\begin{abstract}
The antibiotic resistance in many pathogenic bacteria has become a major clinical problem, therefore, the necessity arises to search for new therapeutic strategies. The most promising solution lies in bacteriophages, phage endolysins and antimicrobial peptides. The aim of this study is to review the possibilities for the common use of bacteriophages, phage endolysins and antimicrobial peptides, both in the form of combined therapies and new strategies for the production of peptide drugs. Bacteriophages are viruses that specifically infect and destroy pathogenic bacteria by penetration into bacterial cells, causing metabolism disorders and, consequently, cell lysis. Phage-encoded endolysins are bacteriolytic proteins produced at the end of the phage lytic cycle that destroy elements of bacterial cell wall and enable the release of phage progeny from host cells. Antimicrobial peptides (AMPs) constitute an element of the innate immunity of living organisms and are characterized by the activity against a broad spectrum of bacteria. In the literature, there are only a few reports on the direct interaction of bacteriophages, phage endolysins and antimicrobial peptides against pathogenic bacteria. In each of them, a synergistic effect was observed, and Phage-encoded antimicrobial peptides as a specific group of AMPs have were also discussed. Phage-display technique was also reviewed in terms of its applications to produce and deliver biologically active peptides. The literature data also suggest that bacteriophages, phage endolysins and antimicrobial peptides can be used in combined therapy, thus negating many of the limitations resulting from their specificity as a single antimicrobial agent.
\end{abstract}

\section{Key words}

bacteriophages, phage endolysins, antimicrobial peptides, synergy, bacterial infections

\section{INTRODUCTION}

For more than half a century, humans have used antibiotics to fight infectious diseases caused by pathogenic bacteria. Excessive use (including in viral and fungal infections) and patients' failure to comply with antibiotic dosing recommendations have led to an increase in the number of antibiotic resistant strains, which is termed the "postantibiotic era" [1]. As a consequence, many resistant pathogens, such as MRSA (methicillin-resistant Staphylococcus aureus), CRE (carbapenem-resistant Enterobacteriaceae), VRE (vancomycin-resistant enterococci) and multi-drug resistant Pseudomonas and Acinetobacter, have become a serious health risk. The rate at which bacteria acquire resistance to antibiotics is also disturbing. It has been shown that Pseudomonas aeruginosa rapidly gains resistance to five important antibiotics after exposure to their increasing concentrations [2]. Antibiotic-resistant strains are also the cause of increased health care costs [3]. In addition, it is expected that in the near future, the number of failures in operations and other medical procedures will increase, due to the occurrence of incurable infections. This may result in a return of the world to the preantibiotic era, where common infections often ended in death.

Addrees for correspondence: Tomasz Mirski, Military Institute of Hygiene and Epidemiology, Poland

E-mail: tomaszmirski@wihe.pulawy.pl

Received: 28.01.2019; accepted: 25.02.2019; first published: 11.04.2019
Considering the above facts, it seems necessary to look for new, therapeutic strategies in combating infections caused mainly by multi-drug resistant (MDR) strains. Bacteriophages and their enzymes or antimicrobial peptides are particularly noteworthy here. They carry a significant advantage over antibiotics and many of them are already used in the treatment of humans and animals. In addition to the advantages, however, there are also drawbacks that may partially limit their use in monotherapy.

\section{OBJECTIVE}

The aim of this study is to review the possibilities for the common use of bacteriophages, their enzymes (endolysins) and antimicrobial peptides, both in the form of combined therapies and new strategies for the production of peptide drugs, with significantly better clinical efficacy.

Characteristics of bacteriophages, phage endolysins and antimicrobial peptides - Bacteriophages. The discovery of bacterial viruses or bacteriophages was one of the most momentous events in microbiology. They were discovered almost simultaneously by Frederick William Twort in England (1915) and Felix d'Herelle in France (1917). However, the first time their lytic activity was observed by the British bacteriologist Ernst Hankin in 1896 [4]. In 2007, more than 
5,500 prokaryotic viruses were described, using electron microscopy, of which bacteriophages accounted for $99.6 \%$ [5]. Thus, phages seem to be, at least theoretically, the largest existing group of viruses. Currently, it is considered that bacteriophages are the most frequently occurring biological particles on earth, and occur in the biosphere in the amount of $10^{30}-10^{32}[4,6]$.

The development of electron microscopy has enabled the very accurate classification of viruses. The first classification of bacteriophages was performed by Bradley (1967) who distinguished three groups of tailed phages and three types of isometric and filamentous phages. The current classification scheme includes 1 order, 13 families and 34 types of bacteriophages [7].

Regarding the type of genetic material found in the capsid, bacteriophages can be divided into four main groups: phages with single-stranded DNA (ssDNA), double-stranded DNA (dsDNA), phages with single-stranded RNA (ssRNA) and double-stranded RNA phages (dsRNA). About $96 \%$ of phages are the tailed type. Polyhedral, filamentous and pleomorphic phages are rare and have a narrow host range [5].

The process of bacterial virus replication may be taking place in the form of a lytic cycle (virulent phage) or a lysogenic cycle (mild phage). The first usually ends with the production of new virions and the destruction of the host cell (lysis); the exception is filamentous phages of the Inoviridae family, which are released continuously without bacterial lysis. In the lysogenic state, the phage genome integrates into the host DNA, or may occur in a free state as a plasmid and becomes latent within the bacterial cell. When this balance is disturbed, the phase of phage production and cell lysis is initiated. The life cycle of virulent tailed phages is a multi-step process involving the adsorption phase, infection of the host cell with phage DNA, the phase of intracellular proliferation and, as a result, the release of new infectious phages [8].

Phage therapy is an alternative way to fight bacteria, including antibiotic-resistant strains. The main properties of phages as antibacterial agents include a specific mechanism of action (different from that of antibiotics), a narrow antibacterial spectrum resulting in the selective killing of pathogenic bacteria, without adversely affecting physiological microflora, and the ability to proliferate at the site of infection $[9,10]$. Other advantages of phage therapy include: efficacy against multi-drug resistant bacteria, the ability to respond rapidly to the emergence of phage-resistant bacterial mutants (much higher frequency of phage mutations than bacteria mutations), lower costs of treatment using phages than antibiotics, and the very rare occurrence of side effects [11]. The high potential of phages for combating antibiotic-resistant bacteria has been demonstrated in many preclinical studies $[12,13,14]$. Potential areas of application of phages include not only clinical medicine, but also the food and agricultural industries $[15,16]$. Phagebased products have been approved by the FDA (Food and Drug Administration) in the field of food safety [17]. In 2006, the first phage product, ListShield, was registered and introduced, being a cocktail of several phages specific to Listeria monocytogenes, contaminating meat and poultry products. Other phage-based products include Listex P100 and AgriPhage for combating the bacterial spotting of tomato and pepper leaves. Furthermore, in 2008, the FDA approved, for the first time, Phase 1 clinical trials using phages. These studies concerned the effect of a cocktail of eight phages against various bacteria, including Staphylococcus aureus, Pseudomonas aeruginosa and Escherichia coli in venous leg ulcers. These attempts have finally confirmed the safety of phage preparations and have paved the way for further clinical trials on phage therapy [18].

However, certain problems are associated with phage therapy. These include: the rapid lysis of bacterial cells that may result in the release of large amounts of endotoxins, the ability to encode toxins by some phages, the lack of pharmacokinetic data, phage neutralization by the host's immune system and conversion of lytic phages to lysogeny (prophages), leading to the "resistance" of bacteria to attack by appropriate lytic phages and possible changes in bacterial virulence.

Endolysins. Bacteriophages have the ability to encode lytic enzymes called peptidoglycan (PG) hydrolases. These enzymes are used to infect and/or release progeny virions from a bacterial host cell. PG hydrolases associated with phage particles may cause so-called "lysis from without", occurring in the absence of a full lytic infection cycle. These lytic structural proteins, mainly associated with the phage tail, cause local cell wall degradation to allow infection of the host cell. In the late stages of the infectious cycle, phages encode PG hydrolases that, together with the holins, are a part of the lytic cassette. Holins cause the perforation of the bacterial cell membrane, thereby allowing the endolysins accumulated in the cytoplasm to gain access to peptidoglycan. The result is the lysis of bacteria and the release of progeny phages [19]. Because this type of PG hydrolases causes "lysis from within" they are referred to as endolysins or lysins.

The structure of endolysins is closely related to the structure of bacterial peptidoglycan. In Gram-negative bacteria, peptidoglycan occurs in the form of a thin layer deprived of surface proteins or carbohydrates. Most of the lysins produced by phages that infect Gram-negative bacteria are globular proteins, with a mass of $15-20 \mathrm{kDa}$ composed of only a single catalytic domain. Gram-positive bacteria have a thick layer of peptidoglycan, which has crossing bonds and surface carbohydrates and proteins. Endolysins of bacteriophages infecting Gram-positive bacteria possess one or more catalytic domains and a binding domain that recognizes epitopes on the surface of cells of target organisms, often causing specific binding to a given strain or species [20]. Typically, the element connecting the catalytic domain to the binding domain is a flexible cross-domain linker sequence [21].

The exogenous action of phage endolysins on bacteria can be used to induce lysis from without due to high osmotic pressure in the cell [22]. This is the starting point for research on the use of purified phage endolysins as antimicrobial agents active against Gram-positive pathogens. In the case of Gram-negative bacteria, due to the presence of an outer membrane, it is usually necessary to use a surfactant, or other additional mechanism that allows the displacement of endolysin through the outer membrane. Nevertheless, there are some reports in the literature regarding the fusion of endolysins with other agents and the resulting activity on Gram-negative bacteria [23, 24, 25].

Antimicrobial peptides. Antimicrobial peptides (AMPs) have been found in almost all living organisms, ranging from bacteria to plants, invertebrates and vertebrates $[26,27,28,29$, 
30,31]. They constitute an element of innate immune response in most species. To date, several hundred natural AMPs have been isolated [32], while several thousands were designed de novo and synthetically produced. Antimicrobial peptides display a wide range of biological activity against bacteria, fungi, protozoa, enveloped viruses and even cancer cells [33, $34,35,36]$. In addition, AMPs possess immunomodulatory properties, essential for innate immunity and inflammatory response [33, 37, 38]. However, the most widely known property of AMPs is their potential antimicrobial activity. In recent decades, antimicrobial peptides have been extensively studied for their use as an alternative to conventional antibiotics, especially for the treatment of infections caused by antibiotic-resistant strains [39, 40, 41].

There is a huge variety of AMPs, resulting from their antimicrobial activity, as well as the various bacterial defence mechanisms they encounter in the host organism [40]. Despite this diversity, antimicrobial peptides have several common features: relatively small size (up to 100 amino acids), the positive charge of the particle conditioned by the presence of arginine, lysine and/or histidine residues, and the ability to assume an amphipathic structure, characterized by the presence of hydrophobic and hydrophilic domains. Due to the positive charge they are also referred to as cationic antimicrobial peptides (CAMPs).

There are several criteria of AMPs classification. Due to the biosynthetic pathway of AMPs, they can be divided into ribosomally and non-ribosomally synthesized. In addition, AMPs are classified based on their origin, secondary structural elements or dominant amino acid residues. One of the most common classifications of AMPs is based on their secondary structure $[42,43]$, on the basis of which four groups of AMPs can be distinguished: linear antimicrobial peptides, with a $\alpha$-helical structure (cecropin A, magainin, LL-37, temporins and several de novo-designed peptides), $\beta$-sheet peptides predominantly stabilized by disulphide bridges (e.g., tachyplesins, protegrins and defensins, such as HBD-1), or by cyclization of the peptide backbone (e.g. polymyxin B and gramicidin $S$ ).

The next group are linear peptides with an extended structure with the predominance of one or more amino acid (indolicidin and bactenecin-5 rich in tryptophan and proline/arginine residues) and peptides with a loop structure, which include lantibiotics (mainly nisin and mersacidin). Lantibiotics are cyclic peptides formed by thioether bridges as a result of post-translational dehydration of the side chains of serine and threonine residues and subsequent reaction with cysteine to form the atypical amino acids lanthionine and methyllanthionine, respectively. Peptides with a loop structure can also be formed by one disulfide bridge (i.e. thanatin, lactoferricin B and bactenecin-1).

The biological activity of AMPs is closely related to their effects on cell membranes. For many of them, it is assumed that the basic, antimicrobial mechanism is the degradation of the cytoplasmic membrane, due to electrostatic attraction by negatively charged functional groups of proteins and phospholipids $[29,44]$. However, there is evidence of the effect of AMPs on the inhibition of certain cellular processes, such as nucleic acid and protein synthesis, enzymatic activity, and cell wall synthesis $[40,45,46]$.

Considering the proposed mechanisms of action of AMPs, it seems that the development of resistance to AMPs in bacteria may be difficult, because it would require drastic changes in the composition and/or organization of the phospholipid membrane [29]. However, some researchers have observed that microbes show the capability to develop resistance to antimicrobial peptides. The main role is played by the mechanisms of proteolytic degradation $[47,48]$, the capture or ejection of AMPs by bacterial cells $[49,50]$, and the partial reduction of the negative surface charge of microorganisms [51]. There are also other mechanisms contributing to the development of bacterial resistance to AMPs, such as the formation of biofilms that confer protection on bacterial cells [52] or a change in the fluidity of the outer membrane of Gram-negative bacteria leading to the reduction of its permeability $[53,54]$.

Direct interaction of bacteriophages, phage endolysins and antimicrobial peptides against pathogenic bacteria. At the moment, there is not much data in the literature on the direct interaction of bacteriophages, phage endolysins and antimicrobial peptides against pathogenic bacteria. The research by Martinez et al. [55], who studied the combined effect of nisin and two lytic phages against Staphylococcus aureus, can be quoted here. A synergistic effect was indeed observed in pasteurized milk used for the studies. However, the appearance of cells resistant to nisin had a negative effect on the activity of bacteriophages, and the nisin-resistant strain had also partially become resistant to both phages. This may have been due to changes in the bacterial cell surface often associated with resistance to nisin and causing interference with the binding/recognition of receptors for phages. The nisin-resistant strain exhibited significantly lower hydrophobic properties and had a higher positive charge, which was expressed by the lack of binding of cytochrome $c$ and nisin. Loss of resistance to nisin restored sensitivity to the phage. In contrast, mutants insensitive to bacteriophage were not resistant to nisin. These results indicate the limited possibility of using nisin in combination with bacteriophages against $S$. aureus, found in dairy products.

The same authors also studied the interaction between phage endolysin LysH5 and nisin against $S$. aureus, and found a strong synergistic effect [56]. The minimum inhibitory concentration (MIC) of nisin and LysH5, determined by the serial microdilution method, was $3 \mu \mathrm{g} / \mathrm{ml}$ and $50 \mathrm{U} / \mathrm{ml}$, respectively. When both components were used in combination, the MIC value for nisin decreased to $0.045 \mu \mathrm{g} / \mathrm{ml}$, and for endolysin to $3.1 \mathrm{U} / \mathrm{ml}$. In addition, nisin increased 8-fold the lytic activity of LysH5 in cell suspension. Synergism observed in vitro was confirmed by the timekill assay in pasteurized milk infected with $S$. aureus. The complete elimination of bacteria was achieved only with the combined action of both agents. This is probably the first study showing the possibilities of a new technology combining endolysin encoded by phage and bacteriocin to effectively inhibit the growth of $S$. aureus in milk.

The current study evaluates the activity of the lipopeptide PAL-KKKK-NH $\mathrm{H}_{2}$ in combination with the bacteriophage EF34 against the E. faecalis 2943 strain, and the activity of the lipopeptides, PAL-KR-NH $\mathrm{H}_{2}$ and MIR-KR-NH $\mathrm{N}_{2}$ in combination with the same phage against the E. faecalis 3584 strain, conducted using the time-kill method [57]. The MIC of peptide PAL-KKKK-NH ${ }_{2}$ against the E. faecalis 2943 strain was $4 \mu \mathrm{g} / \mathrm{ml}$. Using a combination of this peptide with bacteriophage, the reduction of bacterial titre were found to be 10 -fold higher after $1 \mathrm{hr}$, and 100-fold higher after $2 \mathrm{hrs,}$ 
compared to the peptide alone. For the peptide PAL-KR-NH, the MIC against the E. faecalis 3584 strain was $16 \mu \mathrm{g} / \mathrm{ml}$, and when it was used in combination with bacteriophage, a 10 -fold increased reduction of bacterial titre was observed after 15 mins compared to the peptide alone. However, in

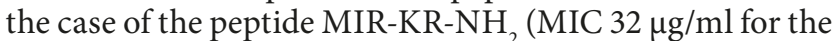
E. faecalis 3584 strain), its use in combination with phage resulted in a 10-fold higher decrease in bacterial titre after 15 mins compared to the peptide alone. After 30 mins of the experiment, the bacterial titre for the peptide-phage combination remained constant, while the peptide alone completely inhibited bacterial growth (unpublished data).

The research team of Shih-Yi Peng [58] synthesized four AMPs based on the amphipathic helical region at the C-terminus of endolysin LysAB2 encoded by Acinetobacter baumannii phage $\Phi A B 2$. These peptides exhibited a strong antibacterial activity against $A$. baumannii (MIC 4-64 $\mu \mathrm{M}$ ), including some MDR and colistin-resistant A. baumannii. Of the four peptides, LysAB2 P3, with modifications that increased its positive net charge and reduced its hydrophobicity, exhibited high antibacterial activity against $A$. baumannii, but low haemolytic and no cytotoxic activity against normal eukaryotic cells. The results of the experiments using electron microscopy and the fluorescein isothiocyanate staining assay indicated that this peptide killed A. baumannii by permeabilization of the membrane. In addition, in a mouse intraperitoneal infection model, at 4 hrs after bacterial injection, LysAB2 P3 reduced 13-fold the amount of bacteria in fluid from the peritoneal cavity, and 27 -fold in blood. In addition, LysAB2 P3 rescued $60 \%$ of mice heavily infected with $A$. baumannii from lethal bacteriaemia. The results confirmed that bacteriophage endolysins are a promising source for the development of effective AMPs.

Phage-encoded antimicrobial peptides as a specific class of anti-infectious agents. In addition to the antimicrobial peptides produced by eukaryotes and bacteria, an additional class of these compounds is known and named phage-encoded AMPs. There are two types of these AMPs: phage-encoded lytic factors and phage tail complexes. Three different types of phage-encoded lytic agents were isolated, all of them derived from phages with small genomes constituting single-stranded DNA or RNA. These factors perform activities similar to elements of the endolysin-holin system of large lytic phages; i.e. induce bacteriolysis to allow release of phage particles into the environment, however, using completely different mechanisms (i.e. non-enzymatic). The examples include $E$ in class $\varphi$ X174 and $L$ in class MS2/GA of RNA phages and $A 2$ in class $\mathrm{Q} \beta / \mathrm{SP}$. The $E$ and $L$ genes encode small membrane proteins, while the $A 2$ protein binds to the host sex pilus playing a secondary role of a lytic agent [59].

Protein $E$, the best-known lytic agent, is a specific inhibitor of the enzymatic reaction catalyzed by the phospho-Nacetylmuramic pentapeptide (MraY) translocase, an integral membrane protein essential for peptidoglycan biosynthesis [60]. It has been shown that the host's peptidyl-prolyl isomerase is necessary for the bacteriolytic activity of $E$ protein [61], and that the bacteriolyse involving the $E$ protein requires continuous division of the host cell, as is the case of penicillin. This data suggests that the mechanism of action of the $E$ protein is very similar to antibiotics [62]. $\mathrm{Yu}$ et al. [63] showed that the 91-amino acid residue of the $E$ protein plays a significant role in the propagation of phage X174 during the lysis of the host cell and can be used to produce so-called "bacterial ghosts". These empty bacterial bodies, lacking cytoplasm and nucleic acids, show excellent immunogenicity and provide effective inducible immunoprotection, and thus can be used directly as vaccines. Analogously, $A 2$ and $L$ proteins encoded by $E$. coli-specific phages Q $\beta$ and MS2 can potentially be used for bacteriainactivating preparation.

Another type of phage-encoded AMPs are the phage tail complexes that are large molecular agglomerates of peptide subunits. These peptides are responsible for the recognition of and binding to specific receptors on the surface of the bacterial cell, and then for penetration through the outer membrane of Gram-negative bacteria and local lysis of peptidoglycan at the site of cell wall binding, and introduction of the phage genome into the host cell. A large number of phage tail proteins have been expressed $[64,65,66]$, and for some of them there are reports regarding their antimicrobial properties $[67,68,69]$. In this light, the possibility of using phage tail complexes as alternative antimicrobial agents seems real, especially in the case of Gram-negative bacteria, where the mechanism of penetrating the outer membrane comes into play.

Application of bacteriophages to produce and deliver biologically active peptides. Recently, progress in the discovery of new drugs has been made through the introduction and development of such technologies as genomics, proteomics and metabolomics. In this context, so-called phage-display technology introduced by G.P. Smith in $1985[70,71]$ probably plays an increasingly important role in the future of pharmaceutical sciences. This technique, using genetic engineering, is based on the production of a phages population (library) to produce peptides of a random sequence, or proteins or antibodies on the surface of the engineered phages. From a large population, the phage that binds to the desired target is selected (biopanning). cDNA sequences randomly introduced into the phage genome are expressed, which leads to the formation of a fusion peptide, connected to a surface protein that builds the bacteriophage coat. In this way, the fusion peptide is displayed outside the virion, while the introduced DNA remains inside the phage particle $[71,72]$. Phage display technology is an effective tool in the discovery of new drugs, mainly due to the identification of ligands with new functions [73].

The development of phage peptide libraries represents a significant advance in the discovery of new components for antibacterial therapy $[74,75]$. The peptides obtained by the phage display technique as ligands for a large spectrum of bacterial enzymes have been extensively studied. Using this technique, well-described enzymes with various structures and functions were selected, and a series of peptides that specifically bound the given factor were isolated. These peptides have been shown to be effective in vitro as inhibitors of enzymatic functions [76]. Thus, isolated peptides can be used to assess enzyme activity or discover antibiotics (as components for the design of peptidomimetics). Based on the fact that lipid A is responsible for all the effects of endotoxin activity, Thomas et al. [77] obtained lipid A-binding peptides by biopanning a library of random pentapeptides displayed on the filamentous phage M-13. The 12 selected peptides were isolated, and analysis of their primary structure showed no matching sequences, suggesting that the lipid A-binding motif 
is not sequentially specific. This is consistent with the observed high variability among natural endotoxin-binding peptides.

Tao et al. used peptides obtained through the phage display technique to inhibit the function of target proteins within the bacterial cell [78]. This researcher selected peptides that bound key targets with a known function that were expressed as fusions with S-glutathione transferase (GST) under the control of a tightly regulated promoter. As a result, inhibition of bacterial growth was obtained by inactivation of specific target proteins.

An interesting issue is also the study of the phage display system for the selection of peptides through biopanning of whole bacteria [79]. This method may allow selection of bacterial membrane ligands with antimicrobial activity from a large peptide library. Such ligands may be complex, socalled dendrimeric peptides, consisting of peptide sequences covalently linked to a branched lysine core [80]. The in vitro and in vivo efficacy of dendrimeric peptides is related to their multimeric nature, which allows multiple interactions. In the medical sciences, dendrimers are a useful tool in many applications, such as antibody analogues, drug transport vectors, anticancer agents, magnetic resonance imaging (MRI) contrast reagents, among others [81].

Pini et al. [79] selected AMPs binding to the whole E. coli cells from a large 10-mer phage peptide library. One of the selected peptides was isolated and synthesized in both monomeric and dendrimeric forms, and it was shown that the antimicrobial activity of the dendrimeric peptide was much higher than the monomeric form. Modification of the original sequence by residue substitution or chain shortening gave three different AMPs with greater resistance to natural degradation and increased bactericidal activity against a wide panel of Gram-negative bacteria. These peptides also showed high resistance to blood proteases, low haemolytic activity and weak cytotoxic effects on eukaryotic cells, which makes them promising as new antibacterial agents.

\section{CONCLUSIONS}

According to the presented review of knowledge on bacteriophages and endolysins, as well as antimicrobial peptides, these agents may constitute a new class of drugs helpful in combating bacterial infections, including those caused by multi-drug resistant strains, thus obtaining a significant advantage over classic antibiotics. In addition to applications in monotherapy, they can also be used in combined therapy, thus negating many of the limitations resulting from their specificity as a single antimicrobial agent. The wide use of lysogenic phages for the expression of peptides with biological activity on their surface indicates that phages can be used as carriers of antimicrobials, antigens or anticancer drugs. However, so far, there is only limited research on the direct interaction of antimicrobial peptides and lytic bacteriophages, or their endolysins against clinically relevant pathogens. This fact indicates the need to undertake this type of research on a wider scale, which could be helpful in the development of new therapeutic strategies to combat severe bacterial infections, which have been a significant problem for a long time, due to the increasing number of strains resistant to classical antibiotic therapy.

\section{REFERENCES}

1. Price NL, Goyette-Desjardins G, Nothaft H, Valguarnera E, Szymanski CM, Segura M, et al. Glycoengineered outer membrane vesicles: a novel platform for bacterial vaccines. Sci Rep. 2016; 6: 24931. https:// doi.org/10.1038/srep24931.

2. Feng Y, Jonker MJ, Moustakas I, Brul S, Ter Kuile BH. Dynamics of mutations during development of resistance by Pseudomonas aeruginosa against five antibiotics. Antimicrob Agents Chemother. 2016; 60(7): 4229-4236. https://doi.org/10.1128/AAC.00434-16.

3. Durai R, Ng PC, Hoque H. Methicillin-resistant Staphylococcus aureus: an update. Aorn J. 2010; 91(5): 599-606. https://doi.org/10.1016/j. aorn.2009.11.065.

4. Ackermann H-W. Bacteriophage electron microscopy. In: Łobocka M, Szybalski WT, editors. Advances in Virus Research. Bacteriophages, Part A, London; 2012. p. 1-32. https://doi.org/10.1016/B978-0-12394621-8.00017-0.

5. Ackermann H-W. 5500 phages examined in the electron microscope. Arch Virol. 2007; 152(2): 227-243. https://doi.org/10.1007/s00705006-0849-1

6. Breitbart M, Rohwer F. Here a virus, there a virus, everywhere the same virus? Trends Microbiol. 2005; 13(6): 278-284. https://doi.org/10.1016/j. tim.2005.04.003.

7. Adriaenssens EM, Edwards R, Nash JHE, Mahadevan P, Seto D, Ackermann HW et al. Integration of genome and proteomic analyses in the classification of Siphoviridae family. Virology. 2015; 477: 144-154. https://doi.org/10.1016/j.virol.2014.10.016.

8. Harada LK, Silva EC, Campos WF, Del Fiol FS, Vila M, Dąbrowska $\mathrm{K}$, et al. Biotechnological applications of bacteriophages. State of the art. Microbiol Res. 2018; 212-213: 38-58. https://doi.org/10.1016/j. micres.2018.04.007.

9. Górski A, Międzybrodzki R, Borysowski J, Weber-Dąbrowska B, Łobocka M, Fortuna W, et al. Bacteriophage therapy for the treatment of infections. Curr Opin Investig Drugs. 2009; 10(8): 766-774.

10. Hanlon GW. Bacteriophages: An appraisal of their role in the treatment of bacterial infections. Int J Antimicrob Agents. 2007; 30(2): 118-128. https://doi.org/10.1016/j.ijantimicag.2007.04.006.

11. Matsuzaki S, Rashel M, Uchiyama J, Sakurai S, Ujihara T, Kuroda M, et al. Bacteriophage therapy: a revitalized therapy against bacterial infectious diseases. J Infect Chemother. 2005; 11(5), 211-219. https:// doi.org/10.1007/s10156-005-0408-9.

12. Biswas B, Adhya S, Washart P, Paul B, Trostel AN, Powell B, et al. Bacteriophage therapy rescues mice bacteremic from a clinical isolate of vancomycin-resistant Enterococcus faecium. Infect Immun. 2002; 70(1): 204-210. https://dx.doi.org/10.1128\%2FIAI.70.1.204-210.2002.

13. Capparelli R, Parlato M, Borriello G, Salvatore P, Iannelli D. Experimental phage therapy against Staphylococcus aureus in mice. Antimicrob Agents Chemother. 2007; 51(8): 2765-2773. https://doi. org/10.1128/AAC.01513-06.

14. Wang J, Hu B, Xu M, Yan Q, Liu S, Zhu X, et al. Use of bacteriophage in the treatment of experimental animal bacteremia from imipenemresistant Pseudomonas aeruginosa. Int J Mol Med. 2006; 17(2): 309-317. https://doi.org/10.3892/ijmm.17.2.309.

15. Balogh B, Jones JB, Iriarte FB, Momol MT. Phage therapy for plant disease control. Curr Pharm Biotechnol. 2010; 11(1): 48-57. https:// doi.org/10.2174/138920110790725302.

16. Mahony J, McAuliffe O, Ross RP, van Sinderen D. Bacteriophages as biocontrol agents of food pathogens. Curr Opin Biotechnol. 2011;22(2): 157-163. https://doi.org/10.1016/j.copbio.2010.10.008.

17. Hunter P. The return of the phage. EMBO Rep. 2011; 13(1): 20-23. https://doi.org/10.1038/embor.2011.234.

18. Wolcott R. A Prospective, randomized, double-blind controlled study of WPP-201 for the safety and efficacy of treatment of venous leg ulcers (WPP-201). U.S. National Library of Medicine. https://clinicaltrials. gov/ct2/show/NCT00663091 (access: 2018.12.07).

19. Young R. Bacteriophage lysis: mechanism and regulation. Microbiol Rev. 1992; 56(3): 430-481.

20. Schmelcher M, Shabarova T, Eugster MR, Eichenseher F, Tchang VS, Banz M, et al. Rapid multiplex detection and differentiation of Listeria cells by use of fluorescent phage endolysin cell wall binding domains. Appl Environ Microbiol. 2010; 76(17): 5745-5756. https:// doi.org/10.1128/AEM.00801-10.

21. Korndorfer IP, Danzer J, Schmelcher M, Zimmer M, Skerra A, Loessner MJ. The crystal structure of the bacteriophage PSA endolysin reveals a unique fold responsible for specific recognition of Listeria cell walls. J Mol Biol. 2006; 364(4): 678-689. https://doi.org/10.1016/j. jmb.2006.08.069. 
22. Seltman G, Holst O. The bacterial cell wall. Springer Verlag (Berlin), 2001.

23. Briers Y, Walmagh M, Lavigne R. Use of bacteriophage endolysin EL188 and outer membrane permeabilizers against Pseudomonas aeruginosa. J Appl Microbiol. 2011; 110(3): 778-785. https://doi.org/10.1111/j.13652672.2010.04931.x.

24. Lai MJ, Lin NT, Hu A, Soo PC, Chen LK, Chen LH, et al. Antibacterial activity of Acinetobacter baumannii phage QAB2 endolysin (LysAB2) against both gram-positive and gram-negative bacteria. Appl Microbiol Biotechnol. 2011; 90(2): 529-539. https://doi.org/10.1007/s00253-0113104-y.

25. Lukacik P, Barnard TJ, Keller PW, Chaturvedi KS, Seddiki N, Fairman JW, et al. Structural engineering of a phage lysin that targets Gramnegative pathogens. Proc Natl Acad Sci U S A. 2012; 109(25): 9857-9862. https://doi.org/10.1073/pnas.1203472109.

26. Broekaert WF, Cammue BPA, DeBolle MFC, Thevissen K, De Samblanx GW, Osborn RW. Antimicrobial peptides from plants. Crit Rev Plant Sci. 1997; 16(3): 297-323. https://doi.org/10.1080/07352689709701952.

27. Ganz T, Lehrer RI. Antimicrobial peptides of vertebrates. Curr Opin Immunol. 1998; 10(1): 41-44. https://doi.org/10.1016/S09527915(98)80029-0.

28. Otvos Jr L. Antibacterial peptides isolated from insects. J Pept Sci. 2000; 6(10): 497-511. https://doi.org/10.1002/10991387(200010)6:10<497::AID-PSC277>3.0.CO;2-W.

29. Zasloff M. Antimicrobial peptides of multicellular organisms. Nature. 2002; 415(6870): 389-395. https://doi.org/10.1038/415389a.

30. Brodgen KA, Ackermann M, McCray Jr PB, Tack BF. Antimicrobial peptides in animals and their role in host defences. Int J Antimicrob Agents. 2003; 22(5): 465-478. https://doi.org/10.1016/S09248579(03)00180-8.

31. Bulet P, Stöcklin R, Menin L. Antimicrobial peptides: from invertebrates to vertebrates. Immunol Rev. 2004; 198(1): 169-184. http://dx.doi. org/10.1111/j.0105-2896.2004.0124.x.

32. Wang G, Li X, Wang Z. APD3: the antimicrobial peptide database as a tool for research and education. Nucleic Acids Res. 2016; 44(D1): D1087-D1093. https://doi.org/10.1093/nar/gkv1278.

33. Hancock REW. Cationic peptides: effectors in innate immunity and novel antimicrobials. Lancet Infect Dis. 2001; 1(3): 156-164. https:// doi.org/10.1016/S1473-3099(01)00092-5.

34. Montesinos E. Antimicrobial peptides and plant disease control. FEMS Microbiol Lett. 2007; 270(1): 1-11. https://doi.org/10.1111/j.15746968.2007.00683.x.

35. Zaiou Z. Multifunctional antimicrobial peptides: therapeutic targets in several human diseases. J Mol Med (Berl). 2007; 85(4): 317-329. https:// doi.org/10.1007/s00109-006-0143-4.

36. Hoskin DW, Ramamoorthy A. Studies on anticancer activities of antimicrobial peptides. Biochim. Biophys. Acta. 2008; 1778(2):357-375. https://doi.org/10.1016/j.bbamem.2007.11.008

37. Auvynet C, Rosentein Y. Multifunctional host defense peptides: Antimicrobial peptides, the small yet big players in innate and adaptive immunity. FEBS J. 2009; 276(22): 6497-6508. https://doi.org/10.1111/ j.1742-4658.2009.07360.x.

38. Lai Y, Gallo RL. AMPed up immunity: how antimicrobial peptides have multiple roles in immune defense. Trends Immunol. 2009; 30(3): 131-141. https://doi.org/10.1016/j.it.2008.12.003.

39. Hancock REW, Patrzykat A. Clinical development of cationic antimicrobial peptides: from natural to novel antibiotics. Curr Drug Targets Infect Disord. 2002; 2(1): 79-83. http://dx.doi. org/10.2174/1568005024605855.

40. Hancock REW, Sahl HG. Antimicrobial and host-defense peptides as new anti-infective therapeutic strategies. Nat Biotechnol. 2006; 24(12): 1551-1557. http://dx.doi.org/10.1038/nbt1267.

41. Peschel A, Sahl HG. The co-evolution of host cationic antimicrobial peptides and microbial resistance. Nat Rev Microbiol. 2006; 4(7): 529-536. http://doi.org/10.1038/nrmicro1441.

42. Epand RM, Vogel HJ. Diversity of antimicrobial peptides and their mechanisms of action. Biochim Biophys Acta. 1999; 1462(1-2): 11-28. https://doi.org/10.1016/S0005-2736(99)00198-4.

43. Van't Hof W, Veerman ECI, Helmerhorst EJ, Amerongen AVN. Antimicrobial peptides: properties and applicability. Biol Chem. 2001; 382(4): 597-619. https://doi.org/10.1515/BC.2001.072.

44. Huang HW. Molecular mechanism of antimicrobial peptides: The origin of cooperativity. Biochim Biophys Acta. 2006; 1758(9): 1292 1302. https://doi.org/10.1016/j.bbamem.2006.02.001.

45. Brodgen KA. Antimicrobial peptides: pore formers or metabolic inhibitors in bacteria? Nat Rev Microbiol. 2005; 3(3): 238-250. http:// doi.org/10.1038/nrmicro1098.
46. Nicolas P. Multifunctional host defense peptides: intracellular-targeting antimicrobial peptides. FEBS J. 2009; 276(22): 6483-6496. https://doi. org/10.1111/j.1742-4658.2009.07359.x.

47. Frick I-M, Nordin SL, Baumgarten M, Mörgelin M, Sørensen OE, Olin AI. Constitutive and inflammation-dependent antimicrobial peptides produced by epithelium are differentially processed and inactivated by the commensal Finegoldia magna and the pathogen Streptococcus pyogenes. J Immunol. 2011; 187(8): 4300-4309. https://doi.org/10.4049/ jimmunol.1004179.

48. Thomassin J-L, Brannon JR, Gibbs BF, Gruenheid S, Le Moual H. OmpT outer membrane proteases of enterohemorrhagic and enteropathogenic Escherichia coli contribute differently to the degradation of human LL-37. Infect Immun. 2012; 80(2): 483-492. https://dx.doi. org/10.1128\%2FIAI.05674-11.

49. Falord M, Karimova G, Hiron A, Msadek S. GraXSR proteins interact with the VraFG ABC transporter to form a five-component system required for cationic antimicrobial peptide sensing and resistance in Staphylococcus aureus. Antimicrob Agents Chemother. 2012; 56(2): 1047-1058. https://doi.org/10.1128/AAC.05054-11.

50. Hiron A, Falord M, Valle J, Débarbouillé M, Msadek T. Bacitracin and nisin resistance in Staphylococcus aureus: a novel pathway involving the BraS/BraR two-component system (SA2417/SA2418) and both the BraD/BraE and VraD/VraE ABC transporters. Mol Microbiol. 2011; 81(3): 602-622. https://doi.org/10.1111/j.1365-2958.2011.07735.x.

51. Ernst CM, Kuhn S, Slavetinsky CJ, Krismer B, Heilbronner S, Gekeler $\mathrm{C}$, et al. The lipid-modifying multiple peptide resistance factor is an oligomer consisting of distinct interacting synthase and flippase subunits. MBio. 2015; 6(1): e02340-14. https://doi.org/10.1128/ mBio.02340-14.

52. Batoni G, Maisetta G, Esin S. Antimicrobial peptides and their interaction with biofilms of medically relevant bacteria. Biochim Biophys Acta. 2016; 1858(5): 1044-1060. https://doi.org/10.1016/j. bbamem.2015.10.013.

53. Matson JS, Yoo HJ, Hakansson K, Dirita VJ. Polymyxin B resistance in El Tor Vibrio cholerae requires lipid acylation catalyzed by MsbB. J Bacteriol. 2010; 192(8): 2044-2052. https://doi.org/10.1128/JB.00023-10.

54. Boll JM, Tucker AT, Klein DR, Beltran AM, Brodbelt JS, Davies BW, et al. Reinforcing lipid A acylation on the cell surface of Acinetobacter baumannii promotes cationic antimicrobial peptide resistance and desiccation survival. MBio. 2015; 6(3): e00478-15. https://doi. org/10.1128/mBio.00478-15.

55. Martinez B, Obeso JM, Rodriguez A, Garcia P. Nisin-bacteriophage crossresistance in Staphylococcus aureus. Int J Food Microbiol. 2008; 122(3): 253-258. https://doi.org/10.1016/j.ijfoodmicro.2008.01.011.

56. Garcia P, Martinez B, Rodriguez L, Rodriguez A. Synergy between the phage endolysin LysH5 and nisin to kill Staphylococcus aureus in pasteurized milk. Int J Food Microbiol. 2010; 141(3): 151-155. https:// doi.org/10.1016/j.ijfoodmicro.2010.04.029.

57. White R, Burgess DS, Manduru M, Bosso JA. Comparison of three different in vitro methods of detecting synergy: time-kill, checkerboard, and E test. Antimicrob Agents Chemother. 1996; 40(8): 1914-1918. http://dx.doi.org/10.1128/AAC.40.8.1914.

58. Peng S-Y, You R-I, Lai M-J, Lin N-T, Chen L-K, Chang K-C. Highly potent antimicrobial modified peptides derived from the Acinetobacter baumannii phage endolysin LysAB2. Sci Rep. 2017; 7(1): 11477. https:// doi.org/10.1038/s41598-017-11832-7.

59. Parisien A, Allain B, Zhang J, Mandeville R, Lan CQ. Novel alternatives to antibiotics: bacteriophages, bacterial cell wall hydrolases, and antimicrobial peptides. J Appl Microbiol. 2008; 104(1): 1-13. https:// doi.org/10.1111/j.1365-2672.2007.03498.x.

60. Mendel S, Holbourn JM, Schouten JA, Bugg TDH. Interaction of the transmembrane domain of lysis protein $\mathrm{E}$ from bacteriophage $\varphi \mathrm{X} 174$ with bacterial translocase MraY and peptidyl-prolyl isomerase SlyD. Microbiology. 2006; 152(Pt 10): 2959-2967. https://doi.org/10.1099/ mic.0.28776-0.

61. Young R, Wang IN, Roof WD. Phages will out: strategies of host cell lysis. Trends Microbiol. 2000; 8(3): 120-128. https://doi.org/10.1016/ S0966-842X(00)01705-4.

62. Bernhardt TG, Wang IN, Struck DK, Young R. Breaking free: "protein antibiotics" and phage lysis. Res Microbiol. 2002; 153(8): 493-501. https://doi.org/10.1016/S0923-2508(02)01330-X.

63. Yu S, Peng W, Si W, Yin L, Liu S, Liu H, et al. Enhancement of bacteriolysis of the shuffled phage PhiX174 gene E. Virol J. 2011; 8(1): 206. https://doi.org/10.1186/1743-422X-8-206

64. Ghequire MGK, De Mot R. The tailocin tale: peeling off phage tails. Trends Microbiol. 2015; 23(10): 587-590. https://doi.org/10.1016/j. tim.2015.07.011. 
65. Noirclerc-Savoye M, Flayhan A, Pereira C, Gallet B, Gans P, Ebel C, et al. Tail proteins of phage T5: investigation of the effect of the His6-tag position, from expression to crystallisation. Protein Expr Purif. 2015; 109: 70-78. https://doi.org/10.1016/j.pep.2015.02.003

66. Granell M, Namura M, Alvira S, Garcia-Doval C, Singh AK, Gutsche I, et al. Crystallization of the carboxy-terminal region of the bacteriophage T4 proximal long tail fibre protein gp34. Acta Crystallogr F Struct Biol Commun. 2014; 70(Pt 7): 970-975. https://doi.org/10.1107/ S2053230X14010449.

67. Hockett KL, Renner T, Baltrus DA. Independent co-option of a tailed bacteriophage into a killing complex in Pseudomonas. MBio. 2015; 6(4): e00452. https://doi.org/10.1128/mBio.00452-15.

68. Liu J, Chen P, Zheng C, Huang YP. Characterization of maltocin P28, a novel phage tail-like bacteriocin from Stenotrophomonas maltophilia. Appl Environ Microbiol. 2013;79(18): 5593-5600. https:// doi.org/10.1128/AEM.01648-13.

69. Gebhart D, Lok S, Clare S, Tomas M, Stares M, Scholl D et al. A modified R-type bacteriocin specifically targeting Clostridium difficile prevents colonization of mice without affecting gut microbiota diversity. MBio. 2015; 6(2): e02368-14. https://doi.org/10.1128/mBio.02368-14.

70. Smith GP. Filamentous fusion phage: novel expression vectors that display cloned antigens on the virion surface. Science. 1985; 228(4705): 1315-1317. http://dx.doi.org/10.1126/science.4001944.

71. Pande J, Szewczyk MM, Grover AK. Phage display: concept, innovations, applications and future. Biotechnol Adv. 2010; 28(6): 849-858. https:// doi.org/10.1016/j.biotechadv.2010.07.004.

72. Hamzeh-Mivehroud M, Alizadeh AA, Morris MB, Church WB, Dastmalchi S. Phage display as a technology delivering on the promise of peptide drug discovery. Drug Discov Today. 2013; 18(23-24): 11441157. https://doi.org/10.1016/j.drudis.2013.09.001
73. Molek P, Strukelj B, Bratkovic T. Peptide phage display as a tool for drug discovery: targeting membrane receptors. Molecules. 2011; 16(1): 857-887. https://doi.org/10.3390/molecules16010857.

74. Christensen DJ, Gottlin EB, Benson RE, Hamilton PT. Phage display for target-based antibacterial drug discovery. Drug Discov Today. 2001; 6(14): 721-727. https://doi.org/10.1016/S1359-6446(01)01853-0.

75. Sanschagrin F, Levesque RC. A specific peptide inhibitor of the class B metallo- $\beta$-lactamase L-1 from Stenotrophomonas maltophilia identified using phage display. J Antimicrob Chemother. 2005; 55(2): 252-255. https://doi.org/10.1093/jac/dkh550.

76. Grøn H, Hyde-DeRuyscher R. Peptides as tools in drug discovery. Curr Opin Drug Disc. 2000; 3(5): 636-645

77. Thomas CJ, Sharma S, Kumar G, Visweswariah SS, Surolia A. Biopanning of endotoxin-specific phage displayed peptides. Biochem Biophys Res Commun. 2003; 307(1): 133-138. https://doi.org/10.1016/ S0006-291X(03)01136-7.

78. Tao J, Wendler P, Connelly G, Lim A, Zhang J, King M, et al. Drug target validation: lethal infection blocked by inducible peptide. Proc Natl Acad Sci U S A. 2000; 97(2): 783-786. https://doi.org/10.1073/pnas.97.2.783.

79. Pini A, Giuliani A, Falciani C, Runci Y, Ricci C, Lelli B, et al. Antimicrobial activity of novel dendrimeric peptides obtained by phage display selection and rational modification. Antimicrob Agents Chemother. 2005; 49(7): 2665-2672. https://doi.org/10.1128/ AAC.49.7.2665-2672.2005.

80. Giuliani A, Pirri G, Nicoletto SF. Antimicrobial peptides: an overview of a promising class of therapeutics. Cent Eur J Biol. 2007; 2(1): 1-33. https://doi.org/10.2478/s11535-007-0010-5.

81. Lee CC, MacKay JA, Fréchet JMJ, Szoka FC. Designing dendrimers for biological applications. Nat Biotechnol. 2005; 23(12): 1517-1526. https://doi.org/10.1038/nbt1171.

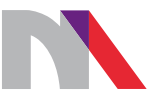

\section{Ministry of Science and Higher Education}

Republic of Poland

Generation of the DOI (Digital Object Identifier) - task financed under the agreement No. 618/P-DUN/2019 by the Minister of Science and Higher Education 